Renewable Agriculture and Food Systems is a multidisciplinary journal which focuses on the science that underpins economically environmentally and socially sustainable approaches to agriculture and food production. The journal publishes original research and review articles on the economic, ecological and environmental impacts of agriculture; the effective use of renewable resources and biodiversity in agro-ecosystems; and the technological and sociological implications of sustainable food systems.
It also contains an open discussion Forum, which presents lively discussions on new and provocative topics. However, the opinions of the Forum and responses are solely those of the authors and do not necessarily reflect the opinions of Renewable Agriculture and Food Systems or Cambridge University Press.

John W. Doran

Editor-in-Chief, RAFS

\title{
Can organic agriculture feed the world?
}

\author{
Catherine Badgley and Ivette Perfecto
}

Forum

The prospect that organic agriculture has the potential to feed the world is welcome news in light of the contradictions of modern agriculture ${ }^{1}$. These include the massive productivity of green-revolution agriculture yet the stubborn persistence of hunger and malnutrition, the loss of small farms even though they are more productive and contribute more to local economies than do large farms ${ }^{2}$, and the pervasive environmental destruction by agricultural biocides and synthetic fertilizers even as more and more ecological services of agricultural landscapes are being recognized $^{3}$. Organic agriculture per se cannot resolve all of these contradictions, but its potential to provide enough food to feed the entire world opens the door to the creation of a new kind of food system based on agroecological production principles. We (Badgley et al. in this issue) have demonstrated two critical points. The first is that the relative yields of organic versus non-organic methods (green-revolution methods in the developed world, lowintensive methods in the developing world) suffice to provide enough calories to support the whole human population eating as it does today. This conclusion is based on a global dataset of 293 yield ratios for plant and animal production. The second point concerns nitrogen fertility. Data from 77 published studies suggest that nitrogen-fixing legumes used as green manures can provide enough biologically fixed nitrogen to replace the entire amount of synthetic nitrogen fertilizer currently in use. Thus, the principal arguments from critics of organic agriculture are invalid. These results are controversial, partly from prejudice and vested interests in the current agricultural system and partly from disputed aspects of the analysis. While this study claims that organic yields and nitrogen fertility methods could feed the world, it does not forecast yields for any particular crop or region, nor does it claim that a global organic food system would necessarily increase food security anywhere. Food security depends on policies and prices as much as on yields.

Our study is not the only one to reach this conclusion. In 1990, Stanhill ${ }^{4}$ came to a similar conclusion about organic production based on a compilation of data from North America and Europe (his average yield ratio was the same as ours for the developed world). More recently, Halberg et al. ${ }^{5}$ modeled scenarios of conversion to organic agriculture in Europe, North America and sub-Saharan Africa, using a globalized market model. They concluded that large-scale conversion to organic agriculture would not severely diminish either the global food supply or food security in developing regions. They noted that food policies favoring local food availability, rather than export crops, would enhance the impact of conversion to organic farming and increase food security in sub-Saharan Africa.

Reviewers raised issues that merit dialogue beyond the context of the article. The first issue concerns the differences in crop-rotation patterns between organic and conventional grain agriculture. The second concerns the reliability of different kinds of sources (i.e. peer-reviewed versus gray literature) for agronomic data.

Rotation effect. Organic grain production frequently uses a different rotation cycle than conventional production. This difference complicates the comparison of yields 
between organic and conventional systems without some kind of time adjustment for grain that must be grown in a longer rotation cycle by organic methods. Corn, wheat and rice, the world's staple grains, are grown in approximately equal quantities (in megagrams) on a global basis $^{6,7}$. In the US, corn and wheat are usually grown in rotation $^{8}$. Corn is typically grown in a longer rotation under organic than conventional methods. For wheat, it is not clear that organic and conventional rotations differ in length. Most rice is grown in irrigated fields so tailored to rice production that other plant crops are not usually included (although green manures and animals can be included); organic and conventional methods for rice do not require different rotations.

Thus, corn is the main crop for which the rotation effect is an issue. A survey of corn/other crop rotations from the sources of yield data cited in Badgley et al. ${ }^{1}$ (this issue) reveals that conventional corn was grown $25-60 \%$ of the time in rotations of 2-6 years, and organic corn was grown $25-50 \%$ of the time in rotations of $2-4$ years. For the sake of a quantitative example, we can determine the yield adjustment for two widely used rotations of corn-a 2-year rotation of corn-soybeans under conventional management and a 3-year rotation of corn-soybeans-wheat + cover crop under organic management. All other things being equal, the organic system would produce only $67 \%$ as much corn as the 2-year conventional system would. If we multiply all of the individual yield ratios for corn in our dataset for the developed world by 0.67 and then recalculate the average yield ratio for grains, the result is 0.84 instead of 0.93 . The reduction in caloric output from the lower average yield ratio for grains in the developed world results in a change from 2641 to 2523 total kcal person $^{-1}$ day $^{-1}$ in Model 1 (based on yield ratios from developed countries) and from 4381 to 4358 total kcal person $^{-1}$ day $^{-1}$ in Model 2 (based on yield ratios from developed and developing countries). Even with this timeadjusted correction for corn, both models generate enough calories (i.e. $>2500 \mathrm{kcal}$ person ${ }^{-1}$ day $^{-1}$ ) to feed the current population. These calculations are conservative since many conventional rotations feature corn less than $50 \%$ of the time. Organic rotations are capable of sustained production of grains rotated with other crops, as demonstrated by the Rodale Farm Systems Trial $^{9}$. A more thorough evaluation of rotation effects requires quantitative comparison of the plot-to-plot yield differences between organic and conventional production and the rate of change in both organic and conventional production methods as a function of the rotation sequence.

Thus, the necessity for different rotation schedules would decrease the production of corn. But since overproduction of corn has depressed the price of corn for many years, this change could actually benefit farmers economically.

Gray literature. A reviewer raised the concern that our quantitative results were suspect because a number of our yield ratios come from the gray literature. Actually,
$74 \%$ of the studies included in our analysis are from peer-reviewed journals. For a study of this sort, which makes a global-scale analysis, it is important to include as many studies as possible from as many regions as possible. We included studies of three kinds: controlled experiments of two or more management methods, paired-farm comparisons in regions with the same soils and climate and comparisons on the same farm before and after a change in management practices. All three kinds of studies could be found in both peer-reviewed and gray-literature sources. It is worth noting that some gray-literature sources are quite reliable, such as the technical reports of respected agricultural experiment stations (the Henry Wallace Experiment Station, Maryland; Kellogg Biological Station's Long-Term Ecological Research Site, Michigan; the Organic Farming Research Foundation, California). Three published works that we consulted for data also cited a mixture of peer-reviewed publications, gray literature and personal communications. Stanhill's ${ }^{4}$ compilation is largely supportive of organic farming, while McDonald et al. ${ }^{10}$ (which focuses just on the system of rice intensification) was skeptical. The third source was the book by Lampkin and Padel ${ }^{11}$, which cites a similar range of sources for yield information. The point is that our compilation is not unusual in the kinds of sources used for analysis.

The most problematic source from the reviewer's standpoint was the report by Pretty and Hine ${ }^{12}$ based on survey data from 52 developing countries. Yields were compared before and after farmers adopted specific agroecological practices. An analysis based on data from this report was subsequently published in Agriculture, Ecosystems and Environment ${ }^{13}$. The main reason for including many of the quantitative comparisons in this report is that relatively few published studies are available from farms in the developing world. In order to evaluate whether the survey data biased our results for the developing world, we performed a significance test on the survey data compared to data from experiments and paired farms. The test failed to reject the null hypothesis that the means in yield ratios do not differ significantly. (This test is explained in detail in Appendix 1 of Badgley et al. ${ }^{1}$.) We concluded that the use of survey data from the report of Pretty and Hine ${ }^{12}$ did not unduly bias our results for the developing world. We note, however, the need for more quantitative, experimental comparisons in developing countries.

One controversial management practice is the system of rice intensification (SRI) in developing countries. Its proponents claim that it boosts yields substantially, while its critics argue that best-management conventional practices perform just as well. A reviewer commented that our cited publications on SRI did not provide the minimum information about soil and environmental conditions for the sites where the studies were performed. This criticism applied to some of the studies cited on both sides of the debate. We tried to avoid bias by using data from both 
proponents and critics in the debate. Furthermore, global estimates by definition involve generalities. Detailed information about soils, climatic conditions and specific management practices was not given for all the studies, regardless of publication source. In principle, these unmeasured variables would favor yields in the conventional system in some instances, while in others they would favor the organic system. There is no reason to think that the lack of information about these variables would bias our study in any particular direction.

In general, we recognize that the high yield ratios from developing countries likely result from the fact that many existing farming practices do not involve optimal amounts of synthetic fertilizer, and may not be managed optimally in numerous other ways. The adoption of organic methods in these settings is a huge improvement. However, our aim is not to demonstrate the superiority of organic farming over conventional agriculture. Our aim is simply to investigate whether organic agriculture can produce enough food to feed the world's population-ours is a sufficiency argument. It is appropriate to use yields from suboptimal existing systems in developing countries, because these systems are representative of much of the developing world and most of the world's farmers.

Going forward. Readers of this journal are well aware of the achievements of alternative agricultural systems both agronomically and economically. These achievements would multiply with additional research on locally suitable cropping systems, fertility methods and pest management for different agricultural regions. Changes in agricultural policy are essential and could foster changes in farming and marketing practices within a few years. As an example, the Cuban food system underwent massive reorganization of farming and marketing methods after the fall of the Soviet Union in $1990^{14}$. After a few years of crisis, exacerbated by the US economic blockade, Cuba now has one of the most progressive food systems in the world. A global food system based on agroecological principles is possible and there are urgent reasons to move in this direction.

\section{References}

1 Badgley, C., Moghtader, J., Quintero, E., Zakem, E., Chappell, M.J., Aviles-Vazquez, K., Samulon, A., and Perfecto, I. 2007. Organic agriculture and the global food supply. Renewable Agriculture and Food Systems 22(2):86-108.

2 Rosset, P. 1999. The multiple functions and benefits of smallfarm agriculture in the context of global trade negotiations. Food First Policy Brief No. 4.
3 Daily, G.C., Alexander, S.E., Ehrlich, P.R., Goulder, L.H., Lubchenco, J., Matson, P.A., Mooney, H.A., Postel, S., Schneider, S.H., Tilman, D., and Woodwell, G.M. 1997. Ecosystem services: benefits supplied to human societies by natural ecosystems. Issues in Ecology 2:1-18.

4 Stanhill, G. 1990. The comparative productivity of organic agriculture. Agriculture, Ecosystems and Environment 30:1-26.

5 Halberg, N., Alrøe, H.F., Knudsen, M.T., and Kristensen, E.S. (eds) 2005. Global Development of Organic Agriculture: Challenges and Promises. CAB International, Wallingford, UK.

6 Clay, J. 2004. World Agriculture and the Environment. Island Press, Washington, DC.

7 Food and Agricultural Organization of the United Nations. 2003. FAO Statistical Database. Available at http://faostat. fao.org/

8 Vesterby, M. and Krupa, K.S. 1997. Major land uses in the United States. Economic Research Service, US Department of Agriculture Statistical Bulletin No. 973.

9 Pimentel, D., Hepperly, P., Hanson, J., Douds, D., and Seidel, R. 2005. Environmental, energetic and economic comparisons of organic and conventional farming systems. BioScience 55:573-582.

10 McDonald, A.J., Hobbs, P.R., and Riha, S.J. 2005. Does the system of rice intensification outperform conventional best management? A synopsis of the empirical record. Field Crops Research 96:31-36.

11 Lampkin, N.H. and Padel, S. (eds) 1994. The Economics of Organic Farming: An International Perspective. CAB International, Wallingford, UK.

12 Pretty, J. and Hine, R. 2001. Reducing Food Poverty with Sustainable Agriculture: A Summary of New Evidence. Final report from the 'SAFE World' Research Project, University of Essex. Available at http://www2.essex.ac.uk/ ces/ResearchProgrammes/SAFEWexecsummfinalreport.htm (accessed 22 February 2007).

13 Pretty, J.N., Morison, J.I.L., and Hine, R.E. 2003. Reducing food poverty by increasing agricultural sustainability in developing countries. Agriculture, Ecosystems and Environment 95:217-234.

14 World Resources Institute. 2000. World Resources 20002001. World Resources Institute, Washington, DC.

Catherine Badgley is a research scientist with the Department of Geological Sciences and the Museum of Paleontology at the University of Michigan, Ann Arbor, MI. Ivette Perfecto is a Professor in the School of Natural Resources and Environment at the University of Michigan, Ann Arbor, MI, USA.

Note: Catherine Badgley and Ivette Perfecto have not had an opportunity to respond to the following comments by Kenneth Cassman and Jim Hendrix. 


\section{Editorial response by Kenneth Cassman: can organic agriculture feed the world-science to the rescue?}

During the past 30 years there has been a steady decrease in funding allocated to agricultural research in both developed and developing countries because of the widespread view that food insecurity is primarily caused by poverty and a lack of purchasing power rather than the inability to produce enough food ${ }^{1}$. However, these views are being challenged by three global mega-trends: (1) a steady decrease in arable land area suitable for intensive food crop production as a result of farmland conversion to urban, industrial and recreational uses, (2) a steady reduction in the relative rate of yield gain for the major cereal cropsyield gains that are falling below the projected rate of increase in cereal demand ${ }^{2}$, and (3) a recent acceleration in the expansion of biofuel production from cereal, sugar and oilseed crops that will divert significant amounts of these crops from the human food supply ${ }^{3}$.

Given these trends, the question of whether organic agriculture can meet current and future food demand at national and global levels is serious business-especially if the answer influences funding priorities for agricultural research ${ }^{4,5}$. Unfortunately, the paper by Badgley et al. ${ }^{6}$ and the associated forum paper by Badgley and Perfecto, both in this issue of RAFS (Vol. 22, No. 2), do not answer this question because their analyses do not meet the minimum scientific requirements for comparing food production capacity in different crop production systems.

Scientific progress depends on published research in peer-reviewed journals-journals that require detailed specification of materials and methods used in the study to allow other scientists to challenge the conclusions and, if necessary, repeat the experiments. For comparisons of cropping systems with different management strategies, the following specifications and data are required:

1. Definition of the systems to be compared. For example, is the goal to compare organic and conventional systems when both utilize the best available technologies and crop rotations for a given field and region? In this case, researchers must strive to identify best management practices that optimize performance of each system separately with regard to input levels and timing of all crop and soil management operations for the specific soil and climatic conditions at the research site. In contrast, most comparisons of organic and conventional systems utilize a relatively customized set of practices for the organic system and standard 'recommended' practices for the conventional system, or practices thought to represent 'average' practices used by conventional crop producers in the region. The problem is that most conventional crop producers also customize crop and soil management practices to their production environment, which can vary substantially from field to field. Hence, a bias exists unless both systems receive the same degree of concern for optimization of all crop and soil management practices, for a given site, within the general guidelines of practices allowed for organic versus conventional systems.

2. Specification of performance parameters as the basis of comparison. The most relevant parameter to address the question of food security is food output per unit areatime. The time dimension is critical because organic systems often require rotations that include non-food crops, such as legume cover crops or lower-yielding legume crops, to provide nitrogen input from symbiotic nitrogen fixation. While yield of the same crop species grown in organic and conventional systems may be similar, total food output of the cropping system may differ depending on the rotation. Further specification of human edible calorie and/or protein yield per unit areatime is also helpful.

3. Quantifying nutrient input levels and equalizing them as required. Organic systems typically rely on manure or compost to satisfy crop nutrient demand and to maintain soil fertility. But release of organically bound nitrogen $(\mathrm{N})$, phosphorus $(\mathrm{P})$ and sulfur $(\mathrm{S})$ in manure depends on biological processes controlled by temperature, moisture and microbial activity. In fact, only a portion of the applied nutrients contained in manure are released during the growing season in which the manure was applied. Likewise, the total amount of nutrients applied in manure is usually much greater than total nutrients applied in conventional systems receiving recommended rates of commercial fertilizer. Over time, the indigenous soil nutrient supply in organic systems often increases compared to that of conventional systems receiving recommended fertilizer rates. Moreover, manure contains all essential plant nutrients in addition to N, P and $\mathrm{K}$-which are the primary nutrients applied in conventional systems. As a result, researchers comparing conventional and organic systems must carefully monitor crop nutrient status to ensure that the conventional system is not deficient in one or more essential nutrient because these deficiencies are easily corrected by application of the appropriate commercial fertilizer. Such measurements are especially important when organic versus conventional comparisons are conducted on soils that do not have high indigenous fertility levels.

4. Appropriate experimental design and treatment replication. Modern statistical methods were initially developed in the first half of the 20th century by agricultural scientists who recognized the challenge of making scientifically sound conclusions based on results from field experiments. Spatial and temporal variation in soil properties and climate require use of statistical theory in experimental design, treatment layout, and replication. Results from field studies that do not adhere to accepted statistical norms are not reliable.

The above specifications and data represent a minimum standard for making reliable comparisons of different 
cropping systems. In my opinion, many of the studies cited by Badgley et al. ${ }^{6}$ fail to meet these standards. Therefore, it is not possible to make sweeping conclusions about the potential for organic systems to feed the world by simply comparing yields between organic and conventional systems. Likewise, even more stringent and comprehensive specifications and data would be required for valid comparisons of the environmental impact of organic versus conventional systems-including the impact on soil quality, water quality as affected by nutrient losses, and greenhouse gas emissions. One cannot simply assume that organic systems are more environmentally sound because they do not use commercial fertilizers and pesticides.

In fairness to those who conducted most of the studies cited by Badgley et al. ${ }^{6}$, the conduct of scientific studies of publishable quality does not appear to be their primary goal. Many seem to be demonstrations and informal trials. While such trials may have educational value, they are not an appropriate basis for scientific inquiry. In conclusion, the question of whether organic systems can feed the world remains unanswered.

Given the need to produce $60 \%$ more food by 2050 to meet demand from growth in both population and income, and to do so with less land and water for irrigation, there is an urgent need for a process of 'ecological intensification' of crop production systems ${ }^{7}$. A focus on existing conventional and emerging organic systems limits the possibilities. Instead, the emphasis should be on developing cropping systems that best contribute to a set of well-defined performance parameters that ensure adequate food supply, farm family income, and protection of environmental quality and natural resources. If a system meets these criteria, it should not matter whether it complies with rules prescribed for organic production systems, or any other arbitrary set of prescriptions for crop and soil management.
The trend of decreasing funds for agricultural research in the public sector dictates a more efficient approach; one that focuses on outputs (broad sense-including environmental impact) from agricultural systems rather than on the type or source of inputs.

\section{References}

1 Drèze, J. and Sen, A. (eds) 1989. Hunger and Public Action. Clarendon Press, Oxford, UK.

2 Cassman, K.G., Dobermann, A.D., and Walters, D.T. 2002. Agroecosystems, $\mathrm{N}$-use efficiency, and $\mathrm{N}$ management. AMBIO 31:132-140.

3 Council for Agricultural Science and Technology (CAST). 2006. Convergence of Agriculture and Energy: Implications for Research and Policy. CAST Commentary QTA 2006-3. CAST, Ames, IA.

4 Cassman, K.G. 2001. Crop science research to assure food security. In J. Nösberger, H.H. Geiger and R.C. Struik (eds). Crop Science: Progress and Prospects. CAB International, Wallingford, UK. p. 33-51.

5 Tilman, D., Cassman, K.G., Matson, P.A., Naylor, R., and Polasky, S. 2002. Agricultural sustainability and intensive production practices. Nature 418:671-677.

6 Badgley, C., Moghtader, J., Quintero, E., Zakem, E., Chappell, M.J., Aviles-Vazquez, K., Samulon, A., and Perfecto, I. 2007. Organic agriculture and the global food supply. Renewable Agriculture and Food Systems 22(2):86-108.

7 Cassman, K.G. 1999. Ecological intensification of cereal production systems: yield potential, soil quality, and precision agriculture. Proceedings of the National Academy of Sciences, USA 96:5952-5959.

Kenneth G. Cassman is the Director of the Nebraska Center for Energy Sciences Research and the B. Keith and Norma F. Heuermann Professor of Agronomy at the University of Nebraska, Lincoln, NE, USA.

\section{Editorial response by Jim Hendrix}

'Farming looks mighty easy when your plow is a pencil and you're a thousand miles from the corn field.' Dwight

\section{Eisenhower}

When Eisenhower made the above observation in 1954, our nation was one to two generations removed from the realities of farming. In the intervening 53 years, certain segments of our society have come to idealize agriculture with a desire to connect to small-scale organic, family-operated farms and to demonize large-scale commercial farms. 'Organic agriculture and the global food supply', by Badgley et al., exemplifies the perspective of some scientists in the academic world who favor organic practices without having a grounded knowledge of the economics and drivers of food production.

I am a large-scale crop producer in the high plains region of Colorado, Kansas, Nebraska and Texas. We utilize center pivot irrigation on coarse sands, practice integrated pest management, and are early and consistent adaptors of technology to substitute capital for labor. We operate several farms utilizing conventional inorganic fertilizers, pesticides, crop rotation and minimal tillage to produce corn, edible beans and alfalfa. I am also involved with a large-scale organic farm and dairy-feeding operation in which we grow grain and alfalfa to produce organic milk. This combination of production practices, employing both organic and inorganic farming techniques, gives me insight into production costs and problems associated with both systems.

The Badgley et al. article misses the mark in several critical areas. In production agriculture, farmers respond to market signals and nitrogen is just one consideration. Organic fertilizer benefits are measured based upon $\mathrm{N}$ content and, in some cases, the content of other nutrients. 
However, these nutrient additions are worth only the sum of their parts; organic nutrients convey no 'magical' properties. Because economics drive production, all sources of nitrogen will be used in the production of food, and combinations of organic and inorganic nitrogen are often used on the same farm. Likewise, the decision to include legumes in a crop rotation is made to maximize economic return and is based upon long-term fertility, current profitability, availability of labor and management, marketing opportunities and a host of other factors.

I question the validity of the statement that production per unit area is greater on small farms than on large farms. 'Large' farms generally maximize land, labor, machinery and management to lower the unit cost of the commodity being produced. Over time, commodities always trade at the average cost of production, leaving little room for producers who are high cost due to low volume.

It is elitist to condemn people to the drudgery of hand labor required on small organic farms; only those who have never done such work believe it is an employment solution. Throughout history, farm producers have sought productivity gains by substituting animal for human labor, designing and employing simple machines and, most recently, using information technology, remote monitoring and sophisticated machinery. It is unreasonable to believe that agriculture will return to hand labor to reduce unemployment or underemployment.

The final fallacy in the Badgley et al. article is the insinuation that organic farming is an advanced method of crop production that always leads to better soil tilth, less erosion and superior nutrition. In our experience, organic corn requires soil tillage prior to planting and cultivation during the growing season to control emerging seedling weeds. These operations destroy organic matter, reduce the water-holding capacity of our light sands and increase soil susceptibility to wind erosion. In contrast, our transgenic corn is planted into winter cover crops which are killed with herbicides after planting. Later, developing weeds are controlled with additional herbicides instead of mechanical cultivation. These conventional farming practices allow us to maintain a protective residue cover on the soil surface and increase soil organic matter inputs.

As a large-scale producer of organic and conventional food products, I would like to share a few insights into the crops that we produce. Generally speaking, as we move into more specialized crops and end products, organic farming becomes more difficult and expensive. For example, there is little difference in the cost of production or yield between organic and inorganic alfalfa. Insect and weed pressures are generally controlled with an early harvest, although this may change with new transgenic alfalfas that offer a longer stand life. On the other hand, dry edible beans are difficult to grow organically. They do not compete well with weeds and are subject to bacterial, fungal and rust infections and insect infestations which can cause considerable loss in both quantity and quality. Furthermore, organic bean yields are typically less than half of those for conventionally grown beans. The primary consumers of dry edible beans are generally unwilling to pay for the higher cost of organic production.

Production issues for organic corn fall somewhere between those for alfalfa and dry edible beans. Producers can access the highest yielding non-transgenic hybrids. In organic corn production, our limiting factor has not been nitrogen or other crop nutrients, even though total fertility costs are about $40 \%$ higher when compared to inorganic forms of fertilizers. Rather, soil insect pressure during stand establishment and the effective control of insects during the growing season have reduced organic corn yields to 80$85 \%$ of conventional. Overall, our cost per unit of production has been approximately $30 \%$ higher for organic compared to conventional corn.

In our operations, the economic driver for organic corn has been the production of a feed source for organic milk. Additional costs associated with organic production have been borne, to date, by the marketplace where wholesale organic milk is currently over twice the price of conventional. Consumers of organic milk believe there is economic and nutritional value in their purchase. Yet, using the latest advances in laboratory testing, we have been unable to demonstrate any difference in the nutrient content between our organic and conventionally produced milk. By purchasing organic milk and other organic products, I also believe that consumers feel they are supporting the idealized image of a small-scale organic, family-operated business. This is rarely the case.

Although economics will dictate how long we produce organic milk, we question the morality and sustainability of organic production. Given its inherently higher cost, are families purchasing less milk to the detriment of young children? Would these children be better served with larger quantities of nutritionally equivalent conventional milk? The same questions can be asked with regard to organic fruits and vegetables.

In the developed world of agriculture, producers respond to market incentives. Given sufficient net returns to attract adequate capital and management, producers will industrialize the production of organic food. We are not driven by ideological concepts, political correctness or environmental persuasions; we are driven by the marketplace. Farmers always respond to incentives in the market and will produce sufficient food using combinations of conventional and organic methods to maximize their individual net returns.

Jim Hendrix is a farmer and President of Progressive Ag Management, Inc., Wray, CO, USA. 